\title{
El Premio Nobel en Fisiología o Medicina, año 2001: avanza el conocimiento del cáncer
}

\author{
Luis A. Gómez \\ Laboratorio de Fisiología Molecular, Instituto Nacional de Salud, Bogotá, D.C., Colombia
}

\begin{abstract}
En octubre de este año, Leland Hartwell, del Centro de Investigaciones en Cáncer Fred Hutchinson, Seattle, Estados Unidos, Paul Nurse y Tymothy Hunt del Imperial Cancer Research Fund, Londres, Reino Unido, fueron laureados con el Premio Nobel en Fisiología o Medicina. En sus trabajos pioneros descubrieron parte de la maquinaria molecular para la regulación del ciclo celular, que está conservada en todos los organismos eucariotes y que ha permitido avanzar en el conocimiento de cómo se dividen las células, con profundas implicaciones en fisiología y medicina. Los trabajos de estos investigadores abrieron una nueva era en la investigación en cáncer y nuevas posibilidades de prevención, diagnóstico y terapia de estas enfermedades.
\end{abstract}

Hartwell, Nurse y Hunt identificaron el mecanismo básico del control de la división celular (proceso por el cual se producen dos células de una única célula) y mostraron que este mecanismo es común a todos los organismos vivientes desde las levaduras hasta los humanos (1). En un cuerpo humano adulto, hay aproximadamente $10^{14}$ células, todas originadas de una única célula, el cigoto fertilizado. Además, millones de células se dividen continuamente reemplazando aquéllas que mueren. Antes de que la célula pueda dividirse, debe crecer en tamaño, duplicar sus cromosomas (estructuras que contienen el material genético) y dividirlos en una distribución exacta entre las dos células hijas. Estos diferentes procesos son finamente coordinados en el ciclo celular (conjunto de estadios o fases secuenciales organizadas y reguladas que genera dos células hijas) de una célula proliferante en el que se describen cuatro

Correspondencia:

Igomez@ins.gov.co

Recibido: 15/11/01; aceptado: 22/11/01 fases: S (por síntesis de DNA), G1 (por Gap 1), M (por mitosis) y G2 (por Gap 2) (figura 1).

Los descubrimientos de Hartwell, Nurse y Hunt, son fundamentales y fueron el punto de partida para la comprensión de la división celular normal, así como para entender que en las neoplasias (crecimiento celular anormal de novo) las células escapan de los mecanismos normales que controlan su división. Este conocimiento tiene un gran impacto sobre todos los aspectos del crecimiento de las células. Los defectos en el control del ciclo celular son una característica de las

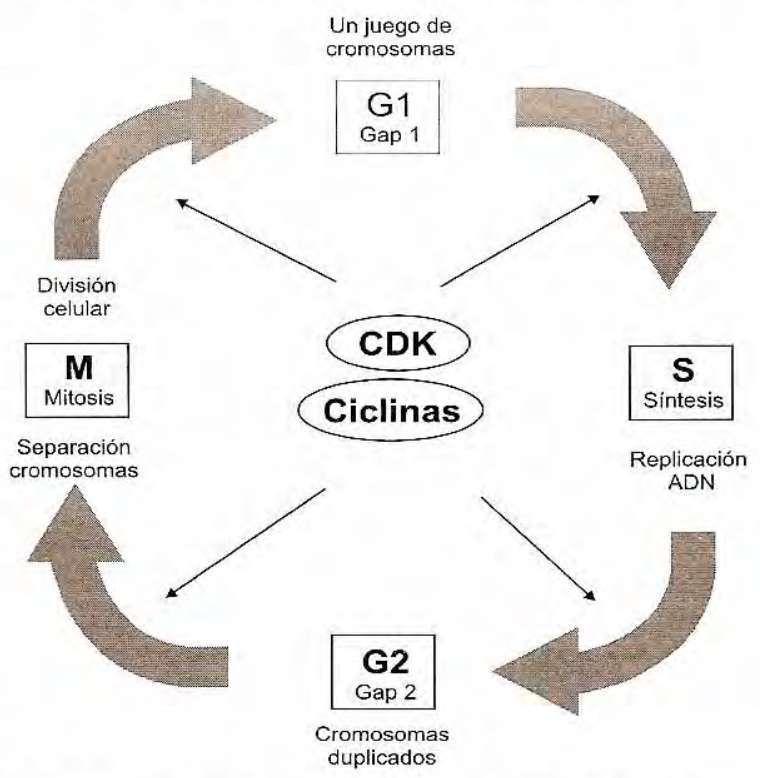

Figura 1. Diagrama de las fases del ciclo celular. En la primera fase (G1), las células crecen. Cuando alcanzan cierto tamaño entran a la fase de sintesis de ADN (S) en donde los cromosomas se duplican. Durante la siguiente fase (G2), la célula se prepara para su división. Durante la última fase, la mitosis (M), los cromosomas se separan y se segregan a las células hijas con exactamente el mismo número de cromosomas. Luego, las células reinician la fase G1 y se completa el ciclo celular de una célula proliferante. 
células tumorales y el conocimiento de los mecanismos moleculares que regulan el ciclo celular ha abierto nuevas posibilidades para el diagnóstico y el tratamiento del cáncer. El ciclo celular que finaliza con la división celular y la generación de las células hijas (M) depende de que cada uno de esos pasos ocurra organizada y secuencialmente (2). Aprender cuándo, cómo y porqué el ciclo celular se altera (conduciendo frecuentemente al crecimiento descontrolado) es una de las piezas centrales del trabajo de estos investigadores.

Leland Hartwell, usando como modelo experimental la levadura Saccharomyces cerevisiae, descubrió una familia de genes que son cruciales para controlar el programa intrincado de instrucciones moleculares con las que una célula crece, se detiene y se divide para autorreplicarse (3). Específicamente, Hartwell en el Departamento de Genética de la Universidad de Washington, descubrió varios de los genes que son esenciales en el desarrollo normal de las levaduras y cuya función es operar sucesivamente para asegurar que la célula se reproduzca de acuerdo con un sistema ordenado en el que una fase (por ejemplo, S) se debe completar antes de que la célula avance hacia la siguiente fase (por ejemplo, G2) y así sucesivamente. Hartwell encontró que uno de estos genes llamado CDC 28/ (cell division cycle) juega un papel central en el control de la transición de $\mathrm{G} 1$ a $\mathrm{S}$ de cada ciclo celular y en la regulación de la progresión a través de los diferentes estadios del ciclo celular. Hartwell también demostró que la replicación del DNA y los eventos nucleares están coordinados con eventos citoplasmáticos en un punto Ilamado START e introdujo el concepto de punto de control, checkpoint, una noción valiosa para entender la regulación normal del ciclo celular, dado que en el curso normal del ciclo de división celular de cualquier organismo pueden ocurrir errores en la síntesis de ADN, daños en el ADN o retrasos en procesos esenciales tales como el ensamblaje de la maquinaria molecular para distribuir los cromosomas en las células hijas (4). Hartwell propuso que los puntos de control capacitan a la célula para monitorizar si se ha completado todo lo que se requiere, así como para hacer reparaciones necesarias, antes de avanzar hacia el siguiente paso y continuar la progresión a través del ciclo. Finalmente, Hartwell sugirió que los defectos en los puntos de control y la inestabilidad genética juegan un papel en la progresión del cáncer (5).

Paul Nurse, por su parte, trabajando con otro modelo experimental, la levadura Schizosaccharomyces pombe, identificó, clonó y caracterizó con tecnología de ADN recombinante y métodos moleculares, tres diferentes proteínas, cada una codificada por diferentes genes y que controlaban la tasa a la cual la célula entraba a la fase $M$. Cada una de esas proteinas actuaban sobre la proteína cdc2 que Nurse reconoció como la proteína reguladora clave de esta fase del ciclo (6). Los trabajos de Nurse no solamente mostraron que los genes CDC28 y cdc2 codifican o producen proteínas que son funcionalmente semejantes una a la otra, sino que también identificó una proteína similar en humanos, una CDK (cyclin dependent kinase; en español, cinasa dependiente de ciclina) $(7,8)$, cuyo papel en las células humanas era análogo al papel de estas proteínas en las levaduras. Además, sus investigaciones Ilevaron a concluir que la proteina CDK dirige a la célula a través del ciclo celular por modificaciones químicas (fosforilación) de otras proteínas (9). Paralelamente, Yoshio Masui de la Universidad de Konan en Japón durante su año sabático en la Universidad de Yale, enfocado en el trabajo experimental en oocitos de anfibio, descubrió un factor promotor de maduración (maturation promoter factor, MPF) en el citoplasma de células que controlaban la división celular en oocitos fertilizados (10). Después, en la Universidad de Toronto, Masui continuó con su investigación y encontró que el MPF es una proteína y después de purificarla y analizar el proceso del ciclo celular encontró que el MPF de los oocitos de anfibio era análogo a las proteínas CDC28 y cdc2 de levadura. Transcurrieron quince años desde la identificación del MPF como un factor que estimulaba el ciclo celular hasta el descubrimiento de su composición bioquímica (11). Con base en esto, una de las contribuciones más importantes de Nurse fue encontrar las conexiones entre los descubrimientos de Hartwell y Masui y la subsiguiente identificación de la proteína similar en humanos. 
De otra parte, Timothy Hunt descubrió las ciclinas, que son proteínas que regulan la función de las CDK. También demostró que las ciclinas son degradadas periódicamente en cada división celular, un mecanismo de importancia general para el control del ciclo celular $(12,13)$. Sus trabajos condujeron a establecer que el ciclo celular y el compromiso de una célula de entrar a la fase So a la fase M están regulados por complejos entre ciclinas y CDK y que los sustratos de la actividad de fosforilación de estos complejos incluyen principalmente factores de transcripción de genes necesarios para la proliferación, diferenciación y viabilidad celular (14).

Como resultado de esos descubrimientos, en los últimos años ha habido una explosión de nuevas investigaciones en esta área de la biomedicina que han conducido a un mejor entendimiento de cómo las células se dividen y qué es lo que se altera en células que llegan a dividirse de una manera descontrolada. El crecimiento celular desregulado (es decir, autónomo) es la característica que define a todas las neoplasias benignas y malignas. Las neoplasias malignas tienen, además, la capacidad de invadir tejidos normales y hacer metástasis. Así mismo, un criterio general es que el tumor tiende a ser menos diferenciado que su tipo celular parental. Por tanto, en cáncer es muy importante, tanto el balance entre la tasa de progresión del ciclo celular (división celular) y la especialización (diferenciación celular) como, la muerte celular programada (apoptosis). El potencial de proliferación, diferenciación y muerte celular parece estar determinado en gran parte por diferencias en la expresión y actividad de genes que pertenecen a varias familias génicas que regulan el ciclo celular (15), tales como ciclinas, cinasas dependientes de ciclinas (CDK), inhibidores de cinasas dependientes de ciclinas $(\mathrm{CKI})$, proteína del retinoblastoma, antígeno nuclear de célula proliferantes (PCNA), proteínas tirosina cinasas (PTK), fosfatasas y factores de transcripción, entre otros (16-18).

Los estudios de Hartwell, Nurse y Hunt han abierto campos de investigación farmacológica y molecular en busca de una mejor comprensión de los procesos básicos que ocurren en las células y del conocimiento de la fisiopatología celular para que se desarrolle el cáncer $(17,18)$. Derivado del trabajo inicial de estos investigadores, también se han generado investigaciones aplicadas órientadas a avanzar en la prevención, en el diagnóstico, en el tratamiento y en la cura del cáncer. Ahora, después de más de 30 años de trabajo con levaduras una de las perspectivas es la aplicación del conocimiento que se ha adquirido y la profundización en el conocimiento de estos mecanismos en células humanas. Actualmente, se están conduciendo investigaciones para el descubrimiento de drogas cuýa acción se fundamenta en el detallado conocimiento del ciclo celular $(18,19)$.

Entendiendo cómo es que el cáncer'ocurre (cómo se inicia, cómo se promueve, cómo crece, cómo evade nuestros sistemas de defensa naturales, cómo progresa y como se puede controlar) seremos capaces de plantear estrategias eficaces para ayudar a las personas con esta enfermedad y también a las que tengan el potencial de desarrollarla. Varios grupos de investigación en el mundo, siguiendo estrategias basadas en mecanismos de control del ciclo celular están investigando blancos moleculares y procedimientos específicos para intervenir directamente en estos mecanismos con el potencial de convertirse en alternativas de prevención y terapia contra el cáncer.

\section{Referencias}

1. Nurse $P$, Masui $Y$, Hartwell $L$. Understanding the cell cycle. Nature Medicine 1998;4:1103-6.

2. Hartwell L, Weinert T. Checkpoints: controls that ensure the order of cell cycle events. Science 1989;246: 629-34.

3. Hartwell LH, Culotti J, Pringle JR, Reid BJ. Genetic control of the cell division cycle in yeast. Science 1974; 83:46-51.

4. Emili A, Schieltz DM, Yates JR, Hartwell LH. Dynamic interaction of DNA damage checkpoint protein Rad53 with chromatin assembly factor Asf1. Molecular Cell 2001; 7:13-20.

5. Hartwell LH. Defects in a cell cycle checkpoint may be responsible for the genomic instability of cancer cells. Cell 1992; 71:543-6.

6. Nurse P. Universal control mechanism regulating onset of M phase. Nature 1990;344:503-8. 
7. Beach D, Durkacz B, Nurse P. Functionally homologous cell cycle control genes in budding and fission yeast. Nature 1982;300:706-9.

8. Lee MG, Nurse P. Complementation used to clone a human homologue of the fission yeast cell cycle control gene cdc2. Nature 1987;327:31-5.

9. Gautier J, Matsikawa T, Nurse P, Maller J. Dephosphorylation and activation of Xenopus p34 ${ }^{\mathrm{cdc} 2}$ protein kinase during the cell cycle. Nature 1989;339:626-9.

10. Masui Y. A cytostatic factor in amphibian oocytes: its extraction and partial characterization. J Exp Zool 1974; $187: 141-7$.

11. Shibuya EK, Masui Y. Fractionation of cytostatic factors from cytosols of amphibian eggs. Dev Biol 1989;135: 212-9.

12. Hunt T. Maturation promoting factor, cyclin and the control of M phase. Curr Opin Cell Biol 1989;1:268-74.
13. Yamano H, Gannon J, Hunt T. The role of proteolysis in cell cycle progression in Schizosaccharomyces pombe. EMBO J 1996;15:5268-5279.

14. Evan GI, Vousden KH. Proliferation, cell cycle and apoptosis in cancer. Nature 2001;411:342-8.

15. Ponder BA. Cancer genetics. Nature 2001;411:336-41.

16. Hanahan D, Weinberg RA. The hallmarks of cancer. Cell 2000;100:57-70.

17. Blume-Jensen $\mathbf{P}$, Hunter t. Oncogenic kinase signalling. Nature 2001;411:341-7.

18. Gómez LA, Vargas E, Escobar LM, Gunturiz ML. Identification of Zis and cyclin D1 genes down regulated with induced melanoma growth suppression. Proceedings of AACR-NCl-EORT 2001;45:222a.

19. Hartwell LH, Szankasi P, Roberts CJ, Murray AW, Friend $\mathrm{SH}$. Integrating genetic approaches into the discovery of anticancer drugs. Science 1997;278:1064-8. 